\title{
Energetic production configuration: its meaning from an environmental point of view
}

\author{
D. Panepinto, G. Genon \& F. Viggiano \\ DIATI Department, Politecnico di Torino, Italy
}

\begin{abstract}
Different configurations for energetic production (only electric and cogenerative) assume a different significance in connection with the different considered criteria. From an economic point of view, in many instances (in particular in the case of the use of a renewable source as fuel), only the electric configuration results are more convenient. From an environmental point of view, a more convenient situation can be obtained with cogenerative configuration.

In this paper, the significance of the two different configurations for energetic production has been examined. The production of electric energy only and the combined production of electric and thermal energy have been evaluated from an environmental point of view.

In order to verify the environmental compatibility of the producing plant, three different tools can be used: the environmental balance, the implementation of the pollutant dispersion model and the tool of the externalities evaluation. More in detail, with the tool of the environmental balance it is possible to perform an evaluation of the flux modification at the stack. Anyway, the results of the environmental balance are not a real index of the effective air quality modification: in order to have an idea of this aspect the implementation of a pollutant dispersion model is required. Finally, the evaluation of externalities is a useful tool in order to have an idea of the social weight of the producing plant.

In this work, after a description of the procedure that can be adopted in order to verify the environmental compatibility of the energy producing plant, we report on two examples of application of this procedure.

Keywords: energy recovery, environmental balance, externalities, dispersion model.
\end{abstract}




\section{Introduction}

The different configurations for energy production from thermal systems (only electric and cogenerative) assume a different significance in connection with the different considered criteria. From an economic point of view, in many instances (in particular in the case of the use of renewable source as fuel), the only electric configuration results the more convenient; instead, from the environmental point of view, the more convenient situation can be obtained with a cogenerative scheme.

In this paper the meaning of the two different energetic production configurations have been examined; the production of electric energy only and the combined production of electric and thermal energy have been considered from the environmental point of view. In particular, two cases have been examined: the first one concerns an environmental comparison for a biomass plant operating in cogenerative configuration, and the second one is directed to a waste incineration plant. In this last case a comparison between the two different energetic recovery configuration, only electric and cogenerative, have been performed.

More in detail, in the first work the proposed construction of a biomass plant for electricity generation in a small city in Piedmont (northern Italy) has been considered, with the goal of cogenerating electricity, destined to immission in the distribution network, and heat, to be sent to a local district heating network; so both electricity and thermal energy can be used. The observed area of interest is the small municipal area where the plant is to be located.

In order to verify the environmental compatibility of the biomass plant, the used tool has been the evaluation of the modification of emissive fluxes at both local and global levels. The new emissive fluxes that would result from biomass plant activation have been evaluated by considering the type of used fuel and the system that is employed for environmental impact containment. In comparison to introduced loads the avoided emission fluxes have been defined, as they result from shutting down of domestic boilers, and from electricity generated and introduced into the electricity network. The calculation is based on known emission factors for different plant schemes, and the thermal power of the current systems is considered for comparison, by using the tools of mass and energy balances. After this balance definition, an external cost analysis has been performed in order to establish the effective advantage or disadvantage of the proposed biomass plant; a modeling of the atmospheric dispersion of the pollutants is very useful in order to obtain indications concerning the real modification of the air quality after the plant activation.

The second considered case analyzes the MSW incineration plant that has been recently built in Turin, and in particular the two different kinds of energy recovery: from one side a recovery of electric energy only (electrical configuration) and on the other side a recovery both of electric and thermal energy (cogenerative configuration). The possibilities of substitution of existing energy generating systems are obviously different. These two different kinds of energy recovery are analyzed by using the following tools: mass and 
energy balance in order to obtain information concerning the advantages or disadvantages deriving from the two different energetic recovery structure, externalities balance, and implementation of pollutant dispersion model.

\section{Adopted methodology}

As it has been indicated, in order to verify the environmental compatibility of a producing plant, we can use three different tools, and in particular the environmental balance, the implementation of the pollutant dispersion model and the tool of the externalities evaluation.

More in detail, with the tool of the environmental balance an evaluation of the flux modification at the stack can be done. The environmental balance is obtained by subtracting to the introduced emission, due to the producing plant, the avoided emissions due to the produced and recovered energy [1-4].

The environmental balance can be computed according to the following formula:

Local/global emissions (added/eliminated)

The "added emissions" are the emissions coming from the combustion plants (incinerator or biomass plant) that will be introduced from waste treatment and renewable energy thermal production, on the contrary, the "eliminated emissions" are the pollutant flow rates that were previously produced by the utilities that can be turned off when the combustion plant operates. As concerns eliminated emissions on global scale, also the emissions produced by centralized electricity conventional thermo-electric plants must be considered, as they are substituted by combustion plant.

More in detail, the added emissions are obtained on the basis of the emissive fluxes and by considering the pollutant concentrations that are fixed by permit at the stack. The eliminated emissions are calculated on the basis of the residential volume that can be connected to the district heating, by taking into account the emission factors [1], and by considering the composition of the fuels actually used.

Anyway, the results of the environmental balance are not a real index of the effective air quality modification: in fact in case of worsening of the environmental balance it is not sure that at this value corresponds, as a final result that can be defined with a model evaluation, a worsening of the air quality; so, in order to have an idea of the real air quality modification, it is necessary the implementation of a pollutant dispersion model [1-4]; in particular in our work the Gaussian Aermod model [6] has been used.

Finally, the evaluation of externalities is a useful tool that can be implemented in order to estimate the social weight of the producing plant [1-4]. In order to obtain this value it is necessary to apply the specific external cost values for each considered pollutant parameter [3], by inserting these values in the environmental balance. By this approach it is possible to evaluate the real external cost arising from the emissions. 


\section{Case study 1: biomass plant}

In the following Tables 1 and 2 the main features (as concerns technical and energetic aspects) of the studied biomass plant are indicated.

Table 1: Main features of the studied plant.

\begin{tabular}{|l|l|l|}
\hline \multicolumn{2}{|l|}{ Fuel } & Biomass - wood pellets \\
\hline \multicolumn{2}{|l|}{ Technology } & Combustion on grate system \\
\hline Energy recovery & boiler \\
\hline Availability & $7.800 \mathrm{~h} / \mathrm{y}$ \\
\hline \multirow{2}{*}{$\begin{array}{l}\text { Treatment of } \\
\text { emissions }\end{array}$} & Dust & ESP (Electrostatic Precipitation) \\
\cline { 2 - 3 } & $\mathrm{NO}_{\mathrm{x}}$ & SNCR (Selective Catalytic Reduction) \\
\cline { 2 - 3 } & $\mathrm{SO}_{\mathrm{x}}$ & Injection of CaOH \\
\hline
\end{tabular}

It is important to highlight that with the reported flue gas treatment line it is possible to obtain concentrations of pollutants in the flue gas in output that are lower than the maximum value indicated by the National Law (D. Lgs. $133 / 2005)$. It is also important highlight that for the domestic boilers that are in part substituted in account of the thermal energy recovered from the plant and transferred to the same users with a district heating network normally there is not the need to adopt a true flue gas purification line, in account of the fact that very often because the existing laws and authorizations do not contain this requirement; by considering this fact, it can be established that the thermal substitution by utilizing biomass plants will lead to an avoided impact.

In Table 2 we report the main features as concerns energy aspects.

Table 2: Summary of the biomass plant energetic data.

\begin{tabular}{|l|l|}
\hline Gross thermal power & $14.6 \mathrm{MW}$ \\
\hline Available thermal power & $13 \mathrm{MW}$ \\
\hline Maximum thermal power & $7.15 \mathrm{MW}$ \\
\hline Maximum required thermal power* & $6.8 \mathrm{MW}$ \\
\hline$*$ this data represent the maximum required thermal power (by considering all \\
the public and private users that are present in the considered area) \\
\hline
\end{tabular}

In the definition of the environmental balance, four different situations have been examined, corresponding to four different scenarios of connection to the district heating system:

- Hypothesis 1: the entire volume of the analyzed town (public and private utilities) will be connected to the district heating network (no distinction between residents and non residents, and no consideration of the aspect of real practical possibility to connect volumes); 
- Hypothesis 2: only the volume of the public and private utilities practically suitable to be connected to the district heating network (no distinction between resident and non-residents) has been considered;

- Hypothesis 3: the total volume corresponding to residents will be connected to the district heating network (no distinction between possibility or not of connection);

- Hypothesis 4: the total volume corresponding to residents and effectively suitable will be considered for connection to the district heating network.

\subsection{Environmental balance}

The initial point was the evaluation of the described hypothesis 1 . The results of the elaborations are reported in Figure 1a). By analyzing this figure it is possible to observe that the environmental impact of plant will be higher in comparison with the load arising from substituted domestic boilers. It is also possible to observe that this impact is very important in particular for the parameters $\mathrm{NO}_{\mathrm{x}}$ (both considering a SNCR system or a SCR system), $\mathrm{SO}_{\mathrm{x}}$ and $\mathrm{CO}$.
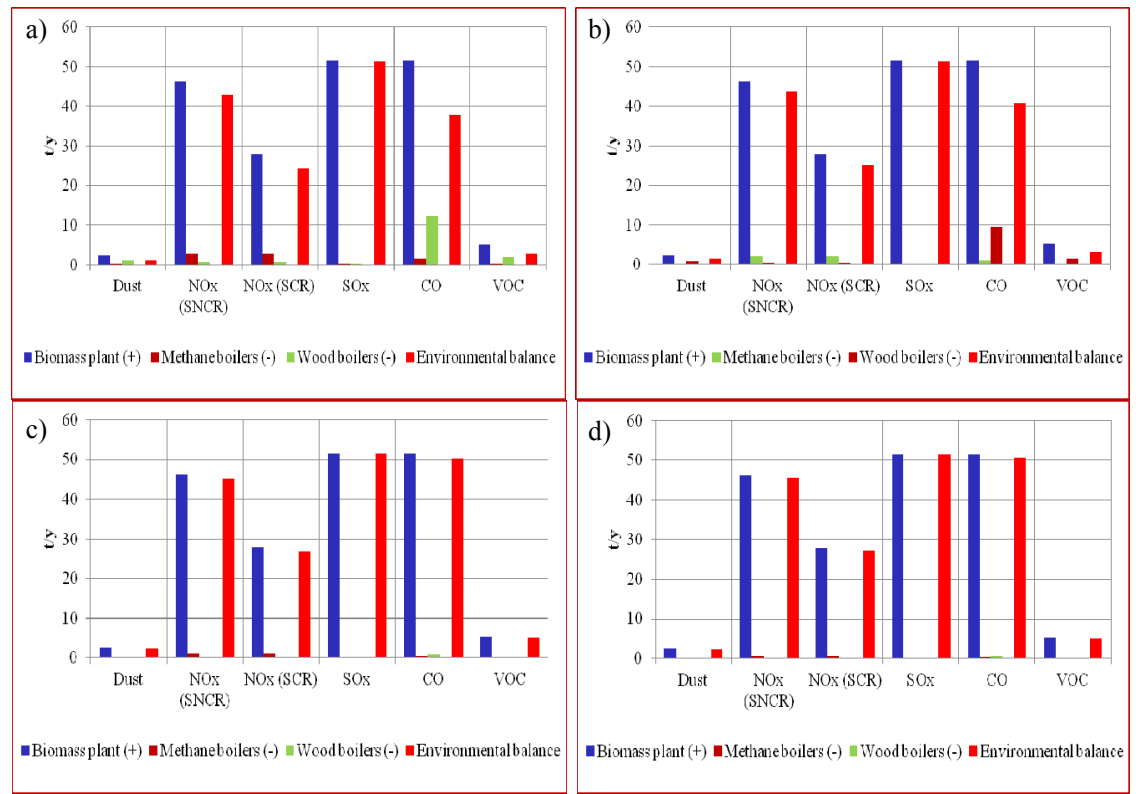

Figure 1: Environmental balance results.

As for hypothesis 2 , in this case it is considered only the volume that really can be connected to the district heating network. By analyzing the results reported in Figure 1b) it is observed that also in this case the pollutant load introduced by the biomass plant is significantly higher in comparison with the avoided one arising from the substitution of the domestic boilers. As in the previous hypothesis, the parameters that mainly suffer from the biomass plant 
introduction are $\mathrm{NO}_{\mathrm{x}}, \mathrm{SO}_{\mathrm{x}}$ and $\mathrm{CO}$; also the parameters dust and $\mathrm{VOC}$ undergo a worsening at balance level, but to a lesser extent.

The hypothesis 3 corresponds to the consideration that only the volumes corresponding to residents will be connected to the district heating network. In Figure 1c) the results referred to this hypothesis are reported; it is possible to see that the trend is similar to the trend of the previous situations.

The hypothesis 4 considers the connection of only volumes for residents and effectively connectable. In Figure 1d) the results relative to this hypothesis are reported.

As expected, in this case, the load introduced by the plant is much higher than the subtracted ones arising from shutdown.

\subsection{External cost analysis}

In Figure 2 the results of the external cost analysis are reported. For simplicity only the results corresponding to hypothesis 1 (as they are the most meaningful) are indicated.
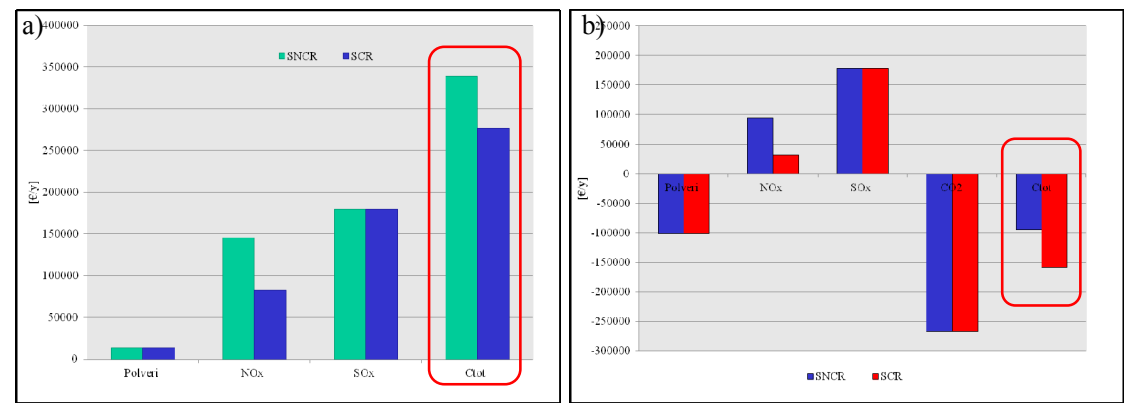

Figure 2: $\quad$ External cost analysis results: a) local scale; b) global scale.

By analyzing the obtained results it is possible to see that from the point of view of the local scale the biomass plant will constitute an added cost for the society while from the point of view of the global scale it will constitute a benefit from the point of view of the external cost. In fact by analyzing Figure $2 b$ ) an avoided social cost can be observed, and this is due, in particular, to the contribution of the parameters dust and, in a large part, carbon dioxide.

\subsection{Pollutant dispersion}

In the following figure, the results of the pollutant dispersion analysis can be seen. Also in this case only the results corresponding to hypothesis 1 are indicated.

By analyzing the results reported in Figure 3 it is possible to see, from the point of view of the dust parameter, a general improvement of the air quality. Also from the point of view of the parameter NOx an improvement of the air quality is observed, this improvement is greater in case of adoption of a SCR 

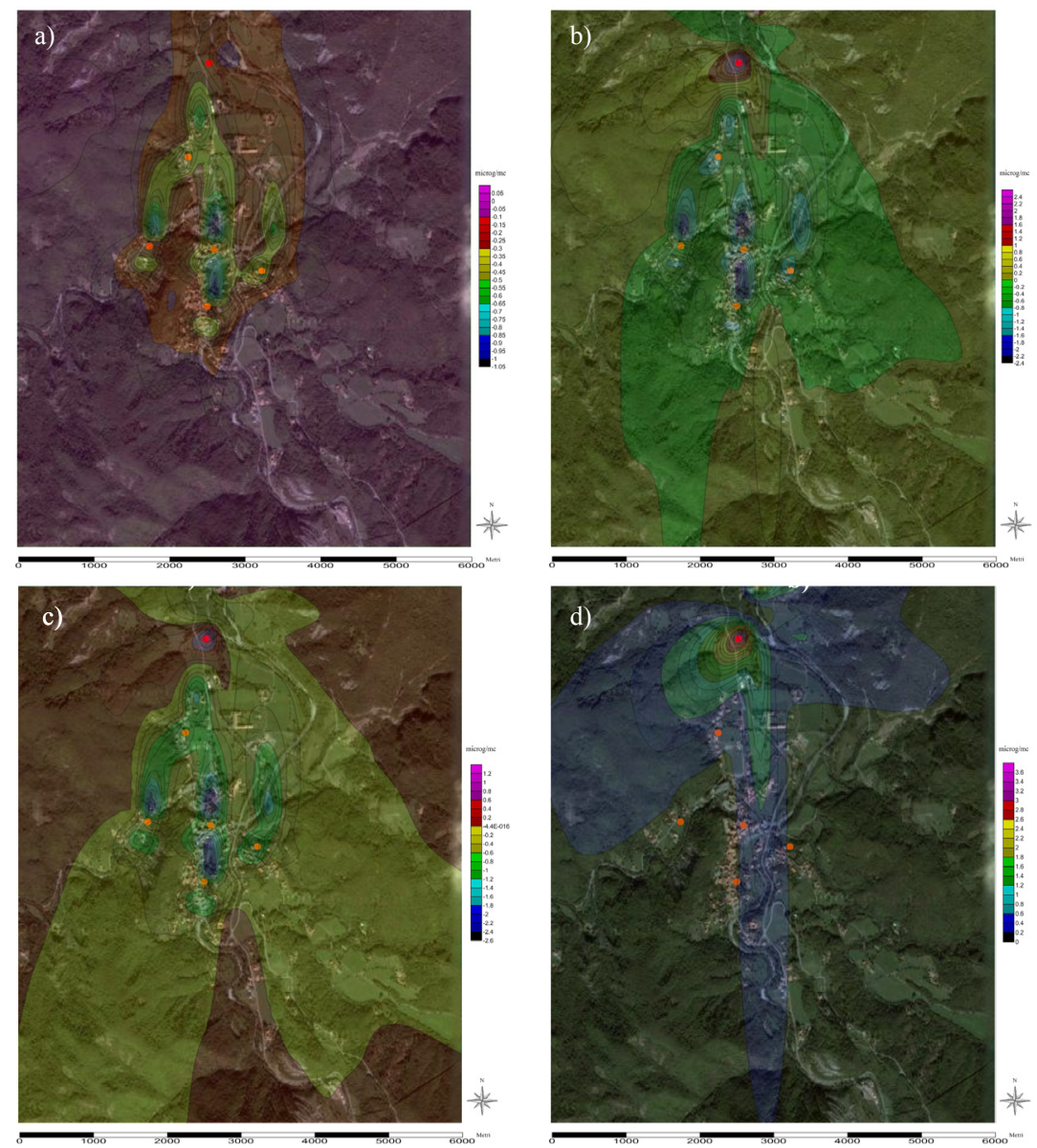

Figure 3: Pollutant dispersion results, parameters: a) dust; b) NOx (with SNCR); c) NOx (with SCR); d) Sox.

(Selective Catalytic Reduction) system for the reduction of the nitrogen oxides. From the point of view of the parameter SOx, instead, there is a general worsening of the air quality consequent to the activation of the plant.

In this analysis only a cogenerative configuration has been considered; in case of only electric configuration the results, from the environmental point of view, are in general less performing that those obtained in case of cogenerative configuration. 


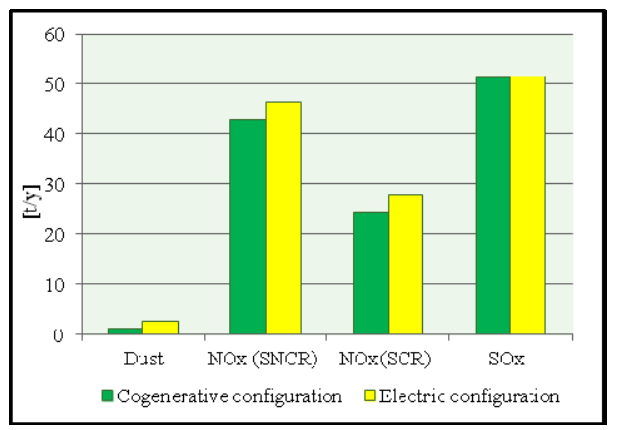

Figure 4: Environmental balance with hypothesis of cogenerative configuration and only electric configuration (local scale).

\section{Case study 2: municipal solid waste plant}

The Turin incineration plant receives $421.000 \mathrm{t} / \mathrm{y}$ of MSW with a LHV = $11 \mathrm{MJ} / \mathrm{kg}$, with the generation of a thermal power of $206 \mathrm{MWth}$. The adopted technology consists in a grate combustor, with a flue gas treatment constituted by an electro filter for the dust reduction, a dry scrubber for the acid gas absorption, with injection of alkali, and a SCR system for the $\mathrm{NO}_{\mathrm{x}}$ reduction. It is important to highlight that with this flue gas treatment scheme it is possible to obtain pollutant concentrations in the flue gas in output that are lower in comparison with the maximum values that are indicated by the National Law (D.Lgs. 133/2005).

Besides waste treatment, energy production is one of the main goals in a modern MSW incinerator. Plant efficiency mainly depends on the boiler limits such as the steam conditions and the flue gas exit temperature. The temperature and pressure of the steam at the turbine inlet are limited by corrosion of the boiler materials. The flue gas treatment requires a strict control of the temperature and water content in flue gas at the boiler exit [5]. In the following table we can see the main energy features considering the two different types of energetic configuration: electric only configuration and cogenerative configuration.

The aim of the elaboration is the definition of the environmental compatibility of the plant in connection with two possible energetic configurations: only electric and cogenerative. In this last case three different hypothesis of connection to the district heating network have been considered:

- Scenario 1: in this case the connection to the district heating network correspond to an house volume of $0.53 \mathrm{Mm}^{3}$;

- Scenario 2: in this case the connection is equal to $6.82 \mathrm{Mm}^{3}$;

- Scenario 3: in this case the connection to the district heating network is increased to $16.30 \mathrm{Mm}^{3}$. 
Table 3: $\quad$ Comparison between the different energetic configurations.

\begin{tabular}{lcc}
\hline Energy production & & \\
\hline & $\begin{array}{c}\text { Electric only } \\
\text { configuration }\end{array}$ & $\begin{array}{c}\text { Cogenerative } \\
\text { configuration }\end{array}$ \\
\hline Total Thermal Power [MW] & 206 & 206 \\
\hline Electric Power [MW] & 62 & 39.5 \\
\hline Thermal Power [MW] & - & 106 \\
\hline Electric Yield [\%] & 30 & 19 \\
\hline Total Yield [\%] & 30 & 70 \\
\hline Saved conventional fuels [TEP/y] & 32,300 & 25,500 \\
\hline
\end{tabular}

\subsection{Environmental balance}

A summary of the results is reported in Figure 5.

By analyzing the obtained results it is possible to see that in the case of only electrical configuration the results are the same for all the considered scenarios.
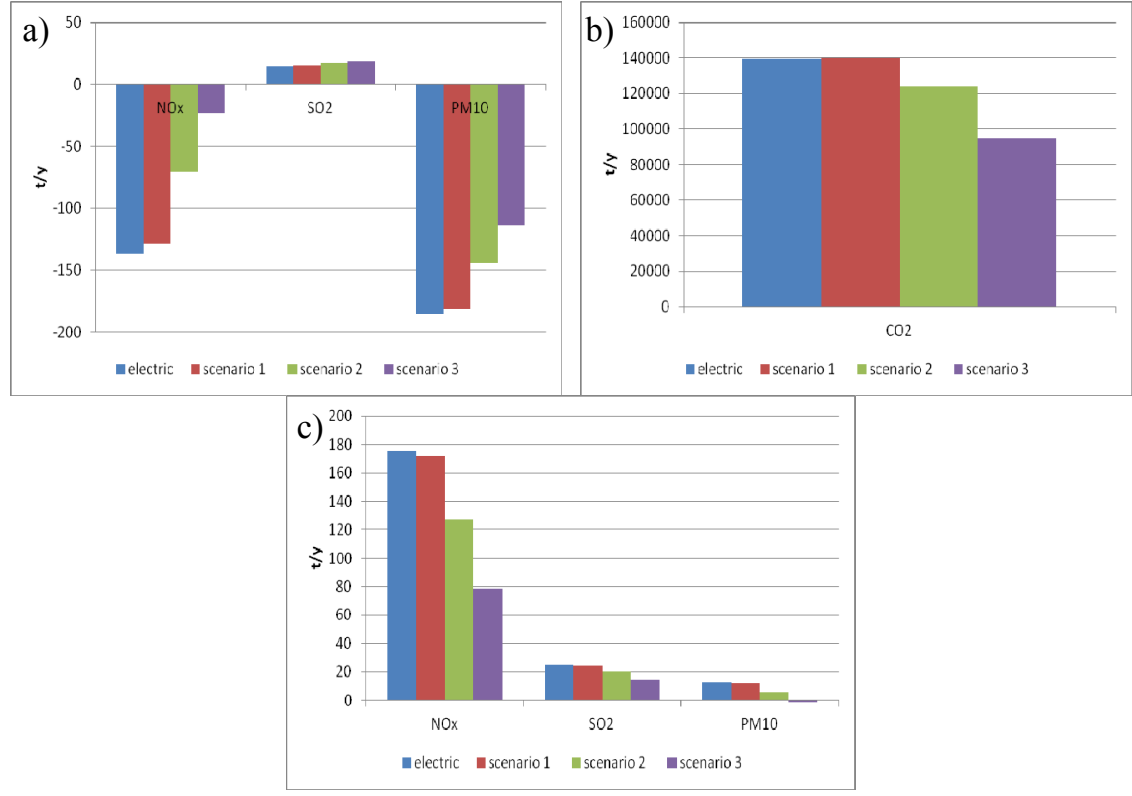

Figure 5: Environmental balance: a) global scale, pollutant parameters $\mathrm{NO}_{\mathrm{x}}$, $\mathrm{SO}_{2}, \mathrm{PM}_{10}$; b) global scale, pollutant parameter $\mathrm{CO}_{2}$; c) local scale.

In the case of cogenerative configuration, the results are quite different; in this case the best scenario is the number 3. By analyzing, for this scenario, the results more in detail, it is observed that from the point of view of the environmental 
balance the best configuration is the cogenerative configuration (on global scale) for the pollutant parameter $\mathrm{CO}_{2}$ and the only electrical configuration for the other parameters.

\subsection{Evaluation of externalities}

From the point of view of the externalities the results are reported in Figure 6.

The obtained results are quite similar to the results obtained as concerns the environmental balance.
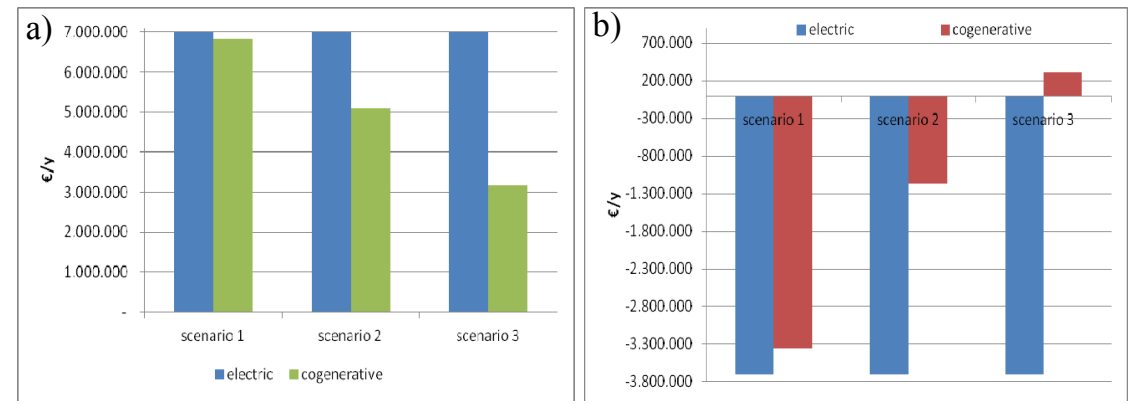

Figure 6: Analysis of externalities: a) comparison between electric and cogenerative configuration on local scale; b) comparison between electric and cogenerative configuration on global scale.

\subsection{Dispersion of pollutants}

In order to evaluate by a model approach the ground level concentration, the adopted steps are:

- it has been constructed a set of concentration maps representing the quality of ground level air consequent to the activation of the incineration plant;

- in the same manner it has been calculated a set of maps referred to the concentrations corresponding to the sources (boilers) that will be eliminated as a consequence of the transfer of thermal power to a district heating network;

- the final result has been obtained by subtracting the two results; i.e. by considering the "added concentrations" minus the "avoided concentrations";

In the following scheme some results corresponding to the simulation as concerns the pollutant parameter $\mathrm{NO}_{\mathrm{x}}$ are reported: in this case the cogenerative scheme has been considered and it has been evaluated the third scenario for connection to the heating network. Figure 7 represents the result for the ground level concentration for the pollutant parameter $\mathrm{NO}_{\mathrm{x}}$ (year mean value).

From the results of the simulation it can be observed that, for the parameter $\mathrm{NOx}$, the maximum ground level concentration (annual mean value) is registered in an hill area near Torino with a value of $1.7 \mu \mathrm{g} / \mathrm{m}^{3}$ (as can be observed with the 


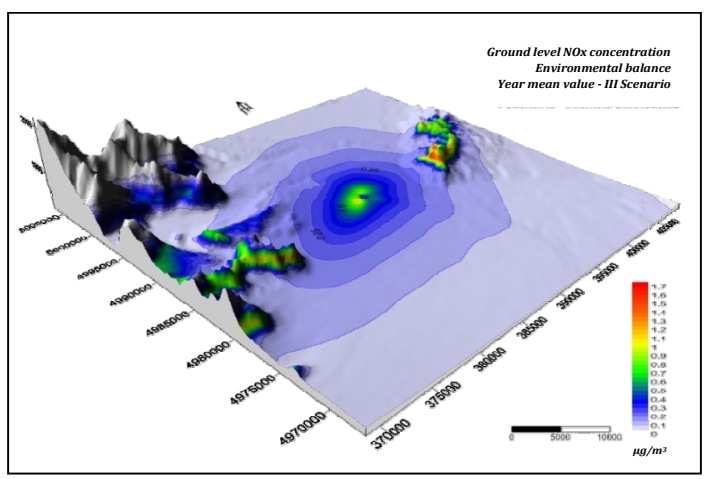

Figure 7: Ground level $\mathrm{NO}_{\mathrm{x}}$ concentration (year mean value).

red color in Figure 7); it must be considered that the maximum value that is allowed from the National law is $40 \mu \mathrm{g} / \mathrm{m}^{3}$ (D. Lgs. 152/2006); from this point of view it can be concluded that the effective plant impact is absolutely low.

As a conclusion, on the basis on the environmental analysis that has been conducted, and by taking also into account the results of another performed analysis (economical analysis), it results that in case of only electric configuration there is an advantage from the economical point of view (by considering that the production of the electric energy from MSW incineration receives an additional bonus), while from the environmental point of view there is an advantage for the cogenerative configuration. On the basis of economic results it can be concluded that in order to obtain a convenience for the cogenerative configuration also from the economic point of view it should be necessary that the thermal energy could be sold at $40 € / \mathrm{MWh}$ instead of $20 € / \mathrm{MWh}$ that is actually evaluated.

\section{Conclusions}

In the present work it has been investigated the meaning of the configuration for energy production in industrial plants from the environmental point of view. In particular two different types of plants have been considered: a biomass combustion plant and a MSW (municipal solid waste) incineration plant.

In the first case (biomass plant) the evaluation concerned the environmental acceptability of a plant for the generation of thermal and electrical energy with biomass combustion in a small city in Piedmont, in Italy. The possible pollution loads that will be introduced have been considered, along with the effect of the elimination of the plants expected to be decommissioned, and in particular the deactivation of a number of public and private boilers. The evaluation was conducted by using the tools of environmental and energy balance, external costs and with a model for dispersion simulation. In consideration of used biomass, existing background loads, such as agriculture, animal husbandry, production activities and transport were not considered. In order to evaluate the air quality modification that would be generated as a consequence of the activation of the 
proposed biomass plant, a pollutant dispersion model has been used. This model description, applied to the case of a plant with cogenerative configuration on a local scale, led to the results of a real improvement of the air quality in terms of dust, a result very different from that derived from the environmental balance analysis concerning the stack emissions. Conversely, in regard to the nitrogen oxides parameter, a general worsening of air quality in the areas near the biomass plant can be observed; also for the sulfur dioxide parameter a net worsening of the air quality, over the entire analyzed area, is observed. In addition, for a better understanding of the overall effects the biomass plant would cause, it was useful to translate the potential damage into monetary terms. The obtained results from the external cost analysis show an improvement, for the plant with a cogenerative configuration.

The aim of the second analyzed case (MSW incineration plant) has been to analyze the wastes incineration plant built in Turin and in particular to compare two different kinds of energy recovery: from one side a recovery only of electric energy (electrical structure) and on the other side a recovery both of electric and thermal energy (cogenerative structure). These two different kinds of energy recovery are analyzed by using the following tools: environmental balance, externalities analysis and pollutant dispersion model.

In general, it can be observed that some advantages both as concerns the local impact and the global impact can be obtained after the realization and connection of the incineration plant. The configuration corresponding to cogeneration leads to a local limitation of the impact, and on the global scale an advantage arises for both the configurations.

\section{References}

[1] Panepinto, D. \& Genon, G., Biomass thermal treatment: energy recovery, environmental compatibility and determination of external costs, Waste and Biomass Valorization, 3, pp. 197-206, 2012.

[2] Panepinto, D. \& Genon, G., Environmental balance study for the construction of a biomass plant in a small town in Piedmont (Northern Italy), WIT Transactions on Ecology and the Environmental, 143, pp. 279-290, 2011.

[3] European Commission edited by Bickel Peter and Friedrich Rainer: ExternE - Externalities of Energy Methodology 2005 Update, Institut für Energiewirtschaft und Rationelle Energieanwendung - IER Universität Stuttgart - Germany, ISBN: $92-79-00423-9,2005$.

[4] Bridgwater, A.V., The technical and economic feasibility of biomass gasification for power generation. Fuel, 74, pp. 631-653, 2005.

[5] European IPPC Bureau, Reference document on best available techniques for waste incineration, 2005, online. http://eippcb.jrc.es/

[6] US Environmental Protection Agency, User's guide for the Industrial Source Complex (ISC3) dispersion models, Volume I - user instructions, http://www.epa.gov/scram001/userg/regmod/isc3v1.pdf. Accessed 20 January 2012 (November 15, 2013). 